\begin{tabular}{|c|c|c|c|c|}
\hline $\begin{array}{c}\text { 118SHARE: SOCIAL WORK } \\
\text { JURNAL }\end{array}$ & VOLUME: 7 & NOMOR: 1 & HALAMAN: $1-129$ & $\begin{array}{l}\text { ISSN:2339 -0042 }(p) \\
\text { ISSN: 2528-1577 }(e)\end{array}$ \\
\hline
\end{tabular}

\title{
PENGARUH BUDAYA JAWA DALAM TARIAN SUNDA KLASIK DI BANDUNG JAWA BARAT
}

\author{
Oleh: \\ Nunung Nurwati ${ }^{1}$, Riyana Rosilawati ${ }^{2}$ \\ 1. Departemen Kesejahteraan Sosial FISIP-Universitas Padjadjaran \\ 2. Mahasiswa Pasca Sarjana FISIP-Universitas Padjadjaran \\ Email: \\ (nunung.nurwati@unpad.ac.id)
}

\begin{abstract}
ABSTRAK
Kesenian tari sunda klasik merupakan salah satu bentuk seni tari yang masih patuh berpegang pada pakem-pakem yang tidak boleh dilanggar, namun seiring dengan adanya proses perubahan sosial, sehingga banyak pakem yang sudah dilanggar. Tulisan ini bermaksud untuk mengkaji bagaimana budaya Jawa mempengaruhi tarian klasik sunda yang ada saat ini di Kota Bandung.

Tulisan ini didasarkan dari hasil penelusuran dokumen-dokumen terkait dengan tema kajia ini bagaimana budaya Jawa mempengaruhi tarian sunda klasik. Dari hasil analisa diketahui proses pengaruh tersebut berlangsung lama, ternyata pengaruh budaya priyayi yang diidentikan dengan perilaku 'alus' yang lebih banyak mempengaruhi tarian sundan klasik. Budaya alus ini berasal dari konsep priyayi yang disimbolkan dengan perilaku yang lemah lembut yang disebut 'alus'. Beberapa tarian sunda klasik yang dipengaruhi budaya 'alus' diantaranya tarian merak dan topeng.

Pola hubungan yang terjadi dari pengaruh tersebut yakni 1) Kerjasama , ini ditandai adanya kontak antara etnis Jawa dan etnis Sunda, 2) Konflik , terjadi pada penerapan pakem atau pelanggaran, dan 3) kompetisi yaitu dalam hal menciptakan karya-karya seni tari.
\end{abstract}

Kata kunci : Etnis, Tarian Sunda Klasik, Indonesia

THE INFLUENCE OF JAVANESE CULTURE ON SUNDANESE CLASSICAL DANCE IN BANDUNG, WEST JAVA

\begin{abstract}
The art of Sundanese Classical Dance is one of the traditional dance that is governed by traditional unbreakable rules. However, social changes have affected the way of the rules to be obeyed, leading to most of the rules has been broken. This paper aims to examine how Javanese Culture influences Sundanese Classical Dance that still in existence in Bandung.
\end{abstract}


This paper is based on the result of document analysis related to the theme of this paper about how Javanese Culture influences the Sundanese Classical Dance. Regarding the result of the analysis, the influence process has been run a long time, which has been dominated by Priyayi people in Indonesia showing their 'Alus' behavior. The 'Alus' behavior comes from the Priyayi concept in Indonesia that symbolized by their gentle and soft behavior. The examples of the Sundanese Classical Dance that have been influenced by 'Alus' culture are Merak Dance and Topeng Dance.

The relation pattern happens that caused by the mentioned influences are 1) Cooperation, characterized by the existence of contact between Sundanese and Javanese ethnicity, 2) Conflict, existing on the implementation and violation of the rule, and 3) Competition, creating the art of dances.

Keywords: Ethnicity, Sundanese Classical Dance, Indonesia

\section{PENDAHULUAN}

Masyarakat Bandung khususnya dan Jawa Barat umumnya mengenal dan menyebut istilah tari Sunda klasik pada beberapa tarian sunda yang ada di kota Bandung, tari-tarian tersebut di antaranya tari merak, topeng, graeni, sulintang, kandagan,puja, sekarputri, dan srigati. Menurut Soedarsono tarian klasik adalah bentuk seni tari yang gerakannya diatur dengan peraturan-peraturan yang mengikat, sehingga seola-olah ada hukum yang tidak boleh dilanggar. Bentuk gerak pada tari klasik ada standarnya, satu gerak yang menyimpang dari standar yang telah ditentukan itu dianggap salah. Dengan demikian pada tari klasik ada standarisasi yang mengikatu, Dengan demikian letak keindahan pada tari klasik ialah pada benar atau tidaknya si penari itu menari menurut standar yang telah ditentukan. Salah satu yang karya yang termasuk kedalam kategori tari klasik adalah hasil karya R.Tjetje Somantri.

Perubahan yang terjadi dalam perkembangan tari ternyata banyak dipengaruhi oleh faktor-faktor non seni, seperti yang dikemukakan oleh Alvin Toffler dalam bukunya yang berjudul "The culture Consumers' menjelaskan bahwa cultural explosion atau ledakan budaya yang ditandai dengan perkembangan ekonomi dapat mempengaruhi seni termasuk seni tari.
R.M Soedarsono dalam sebuah makalah yang berjudul "Dampak perubahan Sosial pada seni Pertunjukan Indonesia" memberikan contoh betapa kuatnya pengaruh perubahan sosial terhadap perkembangan seni pertunjukan di Indonesia. Tahun 1870 Pemerintahan Hindia Balanda memberi peluang kepada siapa saja untuk berkarya dengan bebas dalam bidang khususnya dalam kegiatan ekonomi terutama didaerah yang berkategori urban. Dimana didalamnya tumbuh kreatifitas dalam bidang seni. Saat itu kesenian terutama seni tari dijadikan sebagai tempat untuk menghibur diri dari kegiatan rutin.

Tulisan yang lain R.M Soedarsono juga mengetengahkan bahwa sebagai akibat hadirnya komunitas wisata, maka muncul pertunjukan yang dikemas khusus bagi wisatawan terutama wisatawan mancanegara. Dengan demikian dapat dikatan bahwa berkembangnya seni pertunjukan wisata di Indonesia merupakan akibat dari faktor sosial dan ekonomi (R.M. Soedarsono. 1999-2002).

Beberapa contoh di atas memberikan gambaran, bahwa terjadinya perkembangan atau pembaharuan seni ternyata bukan sematamata disebabkan oleh faktor estetis saja tetapi juga banyak didorong oleh faktor-faktor non seni seperti yang telah dipaparkan di atas, namun walaupun terdapat factor non seni yang 
kuat, tetapi apabila tidak ada tokoh yang mampu jadi pelopor atau secara sosiologis menjadi agen perubahan (agent of change), maka kemunculan karya baru dalam bidang seni tari tidak akan terjadi.

Arah pembaharuan juga bisa pada upaya hadirnya seni pertunjukan yang berlabel nasional, bisa pula merupakan upaya untuk memandang ke depan keluar istana yang oleh sementara para tokoh pembaharu dianggap sebagai pusat berkembangnya seni feodal yang kurang cocok bagi kiprah para pembaharu, dan yang paling maju adalah keinginan untuk menghadirkan karya yang benar-benar memiliki ciri individual penciptanya. Mereka ingin menghadirkan dinamika baru dalam penampilannya baik sebagai penari maupun sebagai koreografer handal yang produktif.

Penampilan tari Sunda klasik di dunia tari Sunda yang banyak membidani karyakarya tari putri juga sangat dipengaruhi oleh faktor-faktor non seni, yaitu faktor sosial dan budaya bahkan faktor politik. Namun di Jawa Barat kehadiran tari-tarian yang berfungsi sebagai hiburan lebih merupakan hiburan kaum pria. Memang pada waktu itu penari wanita mendapat julukan jauh lebih menonjol yang kurang mengenakan yaitu ronggeng. Dominasi kedudukan pria jauh lebih menonjol daripada kaum wanita, bahkan ketika tayub atau tayuban diincar oleh kaum menak Priangan untuk dikembangkan menjadi salah satu identitas "priyayi' Priangan.

Secara historis, pengaruh gaya hidup priyayi Jawa terhadap priyayi Sunda yang lazim disebut menak, telah dibahas secara mendalam oleh Nina Hernina Lubis dalam disertasinya yang berjudul "Kehidupan Menak Priangan Pada Tahun 1800-1942” (1996). Buku ini membahas secara rinci berbagai bentuk dan gaya hidup kaum menak, seperti arsitektur, bahasa, busana,gelar dan seni pertunjukan antara lain ibing keurseus, dan Wayang Wong. Menurut Anis Sujana yang sangat menarik dari tari Keurseus adalah budaya tari yang dimunculkan oleh kaum menak tersebut bersumber dari Tayuban yang sangat digemari oleh masyarakat Jawa.
Walaupun sebenarnya di Jawa Tengah sendiri Tayuban tidak pernah masuk istana, tetapi dalam peristiwa penting seperti pernikahan putra-putri raja Tayuban banyak mewarnai pertunjukan hiburan kalangan pangeran atau priyayi Jawa. Di Jawa Barat, diperhalus diberi nuansa dan dinamika Sunda serta diberikan patokan-patokan tertentu. Dalam hal ini jelas terjadi akulturasi (pembaharuan dan perpaduan kebudayaan kelompok etnis yang bertemu). Seperti pendapat Banton, yang menyatakan bahwa kontak antara dua kelompok ras dapat diikuti proses akulturasi,dominasi, paternalisme, pluralisme, atau integrasi (Kamanto Sunarto, 2000).

Seniman di kota Bandung rupanya peka terhadap keadaan ini yang sangat menyudutkan kaum wanita di kawasan Priangan. Para seniman berusaha mendobrak keadaan yang tertimpang ini dan mereka banyak belajar dari wilayah tetangganya yaitu Jawa tengah (Surakarta dan Yogyakarta) yang menganut faham feodal namun menempatkan penari wanita di Istana, seperti contohnya tari Bedhaya dan Srimpi. Melihat fenomena tersebut maka hal ini secara langsung atau tidak langsung dapat memberi pengaruh yang sangat besar dan berarti dalam pertumbuhan dan perkembangan tari-tarian Sunda klasik (karya Tjetje Somantri) selanjutnya yang dapat dilihat dengan adanya pengaruh etnis Jawa ini.

\section{PENGARUH BUDAYA JWA TERHADAP TARIAN SUNDA KLASIK}

Merasuknya kebudayaan Jawa ke tanah Sunda, jelas berhubungan erat dengan masuknya Sunda ke bawah kekuasaan Mataram pada tahun 1620. Sejak masa itu kontak budaya terjadi, kebudayaan Sunda terutama yang ada di kalangan atas banyak menyadap sumber budaya Jawa baik bahasa, sastra, seni gamelan, wayang dan tari karena menjadi lambang status, lambang peradaban halus kaum menak. (Herlina. 1998). Perubahan penguasa Priangan dari tangan Mataram ke VOC lalu ke pemerintah Hindia Belanda tidak banyak mengubah arah panutan budaya tradisional penguasa di Priangan yang pada beberapa hal masih "menginduk ke Jawa" 
(Yogyakarta dan Surakarta). Karena itu hingga tahun 1941 tidaklah heran jika masih ada Bupati Sunda yaitu bupati Ciamis, RTA. Soenarya yang mengundang guru tari dari Jawa untuk mengajar keluarga Kabupaten menari.

Transformasi kerajaan Sunda yang berubah bentuk pada masa Mataram menjadi kabupaten, kemudian masuk ke dalam sistem birokrasi kolonial pemerintah Hindia Belanda sebagai pemerintahan pribumi atau Inlandsche Bestuur yang dipimpin oleh seorang bupati dan keraton untuk menguasai rakyat. Di bawah jajahan Belanda, keraton dan kabupaten yang sama-sama telah dibatasi kekuasaan dan pengaruhnnya kemudian memusatkan perhatian pada perkembangan kebudayaan sebagai sarana untuk dapat tetap mengagungkan diri. Seperti halnya peran keraton di Jawa, maka pendopo kabupaten di daerah Sunda menjadi pusat kegiatan dan perkembangan seni. Hal ini tidak terlepas dari kebutuhan dari penguasa-penguasa sendiri yaitu para bupati yang hidup seperti raja kecil. Dengan menjadi pengayom kesenian, kaum aristokrasi dapat menonjokan status mereka dengan gaya hidup yang penuh dengan pertunjukan kemegahan. (Herlina. 1998). Sebagai contoh dalam kompleks kabupaten Bandung pada jaman pemerintahan Bupati RRA. Martanegara (1893-1918) ada tempat yang dijadikan "Bale Kebudayaan Priangan". Selain dijadikan semacam museum, tempat ini dijadikan tempat pusat pengembangan seni budaya, seperti: seni tari, seni gamelan, dan sandiwara daerah. Seperti halnya kerajaan di Jawa Tengah dalam menyambut tamu-tamu penting serta acara-acara resmi selalu dipertunjukan adanya tari-tarian. Untuk memenuhi hal-hal tersebut di kabupatenkabupaten diadakan tari Serimpi yang khusus ditarikan oleh putri-putri dan kerabat Bupati, yang berbeda fungsinya dengan Serimpi yang ada di Jawa Tengah. Ungkapan tersebut di tulis pula oleh Ayip Rosidi dalam buku "Ciri-ciri Manusia dan Kebudayaan Sunda"yang menerangkan:

"Pada waktu tatar Sunda ditaklukan oleh sultan Agung, di berbagai kabupaten yang merupakan tempat tinggal Dalem (Bupati), nampak usaha untuk mengikuti pola kehidupan Mataram.......Bentuk kesenian yang pada mulanya menunjukan pengaruh Mataram itu, kemudian berkembang sesuai lingkungan kebudayaan Sunda dan akhirnya menjadi kebudayaan Sunda........Sepanjang sejarahnya ternyata bahwa masyarakat Sunda merupakan masyarakat yang terbuka yang mudah sekali menerima pengaruh dari luar, tetapi kemudian menyerapnya sedemikian rupa sehingga menjadi miliknya sendiri."

Rasa sensitivitas dan kreatifitas para seniman untuk menciptakan tarian Sunda klasik semakin memuncak manakala ia melihat untuk pertama kalinya kira-kira tahun 1925 ada tarian putri karya R.Sambas Wirakusumah di pergelarkan untuk menyambut tamu-tamu penting yang disebut tari Badaya Rancaekek . Jenis tari ini merupakan perkembangan dari tari Kawitan yang diciptakan khusus untuk tari putri rampak (kelompok). Tari Badaya ini berbeda dengan tari Badaya yang terdapat di Keraton Cirebon atau Keraton Jawa Tengah, nama Badaya di tatar Sunda beda artinya dengan yang ada di Jawa Tengah, Badaya ini diambil dari nama gending pengiring tarian yaitu lagu Kawitan naik Badaya. Keadaan seperti ini memacu seniman untuk menciptakan tari-tarian putri yang semula penari-penari putri dilarang tampil karena konotasi yang kurang bagus, lambat laun keadaan ini hilang dengan sendirinya malahan menggeser kehidupan penari dan kehidupan tari putra di Jawa Barat. Oleh sebab itu tari Sunda klasik yaitu sebagai pembaharuan dari tari sunda yang ada sebelumnya, dan berhasil merubah image budaya Sunda, serta merta berhasil pula membawa tari-tarian putri sebagai tari Sunda klasik, dan menjadi andalannya tidak saja di Jawa Barat bahkan sampai ke luar negeri. Dalam hal ini penulis sependapat dengan teori konflik dari Coser (dalam Johnson: 1990) yang menyebutkan bahwa tidak selamanya konflik itu berkonotasi negatif, sebaliknya konflik sosial dapat 
menjadikan penguat kelompok sosial. Konflik dengan masyarakat lain (out group) dapat memulihkan integrasi masyarakat internal (in group). Hal ini sejalan dengan pendapat Collins (dalam Maliki, 2003) dimana konflik dapat membantu mewujudkan kesatuan atau membangun kembali kesatuan dalam kelompok. Menurut pendapat penulis konflik yang dapat diselesaikan oleh para seniman melalui pembaharuan dalam tari-tarian Sunda klasik yaitu dapat mengubah citra wanita yang apabila menjadi penari dianggap sebagai "ronggeng" yang berkonotasi kurang baik menjadi dapat mengangkat/mengubah citra wanita sebagai penari yang dihormati/dihargai.

Penulis berpendapat bahwa apa yang dilakukan oleh para seniman dalam perjuangan menghidupkan tari-tarian putri sebagai tari Sunda klasik dapat dikatakan sebagai perjuangan yang sangat berarti, yang dapat menbawa harum nama Bangsa Indonesia. Hal ini sesuai dengan pendapat Coser tentang konflik (dalam zeitlim, 1998) yang mengemukakan bahwa konflik mengandung arti perjuangan nilai dan penyaluran terhadap status yang langka, kemudian kekuasaan dan sumber-sumber pertentangan di netralisir atau dieliminir saingan-saingannya. Disini penulis berpendapat bahwa secara langsung atau tidak langsung, tindakan itu merupakan perbuatan yang menjunjung tinggi nilai-nilai luhur yang terkandung dalam kesenian khususnya tari (nilai filosofi dan nilai estetis). Dibalik gemerlapnya keberhasilan tari Sunda klasik dalam dunia tari ada dua hal penting dan menarik untuk dikemukakan yaitu mengenai isi filosofis atau ajaran spiritual di balik gerakgerik ragawi dari sikap dan gerak tari yang diciptakan dalam tari klasik.

Pengaruh yang sangat terasa dalam proses penciptaan karya tari Sunda klasik selanjutnya terlihat jelas pada bentuk-bentuk tariannya, yang semula tarian-tariannya didominasi oleh tari-tarian putra. Diperkirakan keadaan seperti ini disebabkan begitu suburnya tari-tarian Sunda yang berfungsi sebagai hiburan pribadi, seperti:Ibing Keurseus, tari Topeng, Bajidoran, Ronggeng dan lain-lain. Yang selalu menempatkan wanita dalam posisi kurang terhormat. Padahal, di istana-istana Jawa Tengah penari wanita yang disebut Bedaya merupakan komunitas yang memiliki kedudukan yang sangat terhormat. Inilah yang menyebabkan munculnya tari Sunda klasik untuk mengangkat citra wanita Sunda di panggung pertunjukan, walaupun konteks yang sangat berbeda dengan kedudukan penari Bedaya di istana Jawa Tengah. Konsep alus menjadi acuan dalam mengangkat citra wanita Sunda di panggung pertunjukan, dan dalam tari Sunda klasik banyak meminjam ragam-ragam gerak dan busana dari Jawa.

Dengan demikian, tampaklah betapa besar pengaruh budaya "Priyayi" dan tari Jawa dalam proses pembentukan tari Sunda klasik. walaupun demikian, dalam berbagai aspek tampak sekali pengaruh itu tetapi sebagai bentuk dan gaya seni yang utuh tari Sunda tetap memiliki citra penampilan serta rasa Sunda. Hal ini disebabkan oleh adanya perbedaan ciri-ciri dan sifat serta etnis Jawa dan etnis Sunda. Manusia Sunda lebih sedikit bersifat ekstrover daripada manusia Jawa tradisional yang bersifat sangat introver. Sifat ini menghadirkan tingkah laku orang Sunda yang lebih dinamis dari pada orang Jawa. Dampaknya tari Sunda klasik terkesan menjadi lebih dinamis. Untuk mencermati seberapa jauh persaman dan perbedaan antara dua gaya dari yang memiliki hubungan historis dan kultural ini sangat diperlukan pencermatan yang lebih mendalam.

\section{PENUTUP}

Berdasarkan hasil analisa dapat disimpulkan sebagai berikut; proses pengaruh budaya jawa terhadap tari sunda klasik terjadi dalam waktu yang lama. Budaya priyayi kareton jawa dengan konsep 'alus' pada gerak tari sunda klasik. Ada tiga pola hubungan yaitu adanya 1) Kerjasama atau kontak antara etnis Jawa dan etnis Sunda, 2) Konflik yang terjadi tidak secara kasat mata saling kontra tetapi lebih ke konflik secara tidak langsung tetapi lebih pemulihan/penyerapan nilai-nilai yang cocok untuk diterapkan pada etnis Sunda dan 3) kompetisi. Kegigihan dalam untuk menciptakan karya-karya. Tari sunda klasik 


\begin{tabular}{|c|c|c|c|c|}
\hline $\begin{array}{c}\text { 118SHARE: SOCIAL WORK } \\
\text { JURNAL }\end{array}$ & VOLUME: 7 & NOMOR: 1 & HALAMAN: 1 - 129 & $\begin{array}{l}\text { ISSN:2339 -0042 }(p) \\
\text { ISSN: 2528-1577 }(e)\end{array}$ \\
\hline
\end{tabular}

mengambil dan menyerap budaya priyayi /menak Jawa Tengah dengan konsep alusnya.Konsep alus yang terjadi karena etnis yang berbeda, hasilnya bukanlah tari Jawa bergaya Sunda, tetapi tetap sebagai tari Sunda klasik.

\section{DAFTAR PUSTAKA}

Bandem, I Made dan Eugene Fredrik. 1995. Balinese Dance Transition. Kuala Lumpur: Oxford University.

Caturwati, Endang. 2000. R.Tietje Somantri (1892-1963) Tokoh pembaharu Tari Sunda. Yogyakarta: Tarawang.

Herlina, Nina. 1998. Kehidupan Kaum Menak Priangan 1800-1942. Bandung: Pusat Informasi Kebudayaan Sunda.

Martin, John. 1965. The Modern Dance. New York: Dance Horizons

Martodirdjo, Haryo. 2009. Hubungan Antar Etnik. Makalah yang disajikan pada perkuliahan di Pasca jurusan Sosiologi Antropologi UNPAD Bandung.

Narawati, Tati. 2003. Wajah Tari Sunda dari Masa. Bandung: P4ST UPI.'Riwayat Belajar Tari-Tarian Djawa". Dalam Jurnal Budaya Bahasa Indonesia (November 1948).

Rosidi, Ayip. 1960. "Ciri-Ciri Manusia dan Kebudayaan Sunda”. Dalam Edi S. Ekadjati, Masyarakat Sunda dan Kebudayaannya. Jakarta: Giri Mukti Pataka.

Soedarsono. 1972. Djawa dan Bali. Yogyakarta: Gadjah Mada Press. 